\title{
Assessing landscape functional connectivity in a forest carnivore using path selection functions
}

\author{
Filipe Carvalho $\cdot$ Rafael Carvalho • \\ António Mira $\cdot$ Pedro Beja
}

Received: 10 February 2015/Accepted: 10 December 2015/Published online: 21 December 2015

(C) Springer Science+Business Media Dordrecht 2015

\begin{abstract}
Context Understanding connectivity patterns in relation to habitat fragmentation is essential to landscape management. However, connectivity is often judged from expert opinion or species occurrence patterns, with very few studies considering the actual movements of individuals. Path selection functions provide a promising tool to infer functional connectivity from animal movement data, but its practical application remains scanty.

Objectives We aimed to describe functional connectivity patterns in a forest carnivore using path-level
\end{abstract}

Electronic supplementary material The online version of this article (doi:10.1007/s10980-015-0326-x) contains supplementary material, which is available to authorized users.

F. Carvalho $(\square) \cdot$ R. Carvalho $\cdot$ A. Mira

Conservation Biology Unit (UBC), Biology Department, University of Évora, Núcleo da Mitra, 7002-554 Évora, Portugal

e-mail: filipescpcarvalho@gmail.com

F. Carvalho $\cdot$ R. Carvalho $\cdot$ A. Mira

Research Center in Biodiversity and Genetic Resources (CIBIO/InBIO), University of Évora, Pólo de Évora, Casa do Cordovil $2^{\circ}$ Andar, 7000-890 Évora, Portugal

F. Carvalho

Ecosystems Functioning and Conservation (FEC),

Institute of Mediterranean Agricultural and

Environmental Sciences (ICAAM), University of Évora,

Pólo da Mitra, 7002-554 Évora, Portugal analysis, and to explore how connectivity is affected by land cover patterns and road networks.

Methods We radiotracked 22 common genets in a mixed forest-agricultural landscape of southern Portugal. We developed path selection functions discriminating between observed and random paths in relation to landscape variables. These functions were used together with land cover information to map conductance surfaces.

Results Genets moved preferentially within forest patches and close to riparian habitats. Functional connectivity declined with increasing road density, but increased with the proximity of culverts, viaducts and bridges. Functional connectivity was favoured by large forest patches, and by the presence of riparian areas providing corridors within open agricultural

\section{F. Carvalho}

Department of Zoology and Entomology, School of Biological and Environmental Sciences, University of Fort Hare, Private Bag X1314, Alice 5700, South Africa

P. Beja

EDP Biodiversity Chair, Research Center in Biodiversity and Genetic Resources (CIBIO/InBIO), University of Porto, Campus Agrário de Vairão, 4485-661 Vairão, Portugal 